Témoigner Témoigner. Entre histoire et mémoire

Getuigen Revue pluridisciplinaire de la Fondation Auschwitz

$127 \mid 2018$

Perpétuation de la violence après 1918

\title{
"The Shop on The High Street" (Jan Kadar \& Elmar Klos) : Een les in provinciaal opportunisme
}

"Le miroir aux alouettes" (Jan Kadar et Elmar Klos) : une leçon sur

l'opportunisme provincial

\section{Brecht Capiau}

\section{(2) OpenEdition}

Journals

Édition électronique

URL : https://journals.openedition.org/temoigner/7699

DOI : $10.4000 /$ temoigner.7699

ISSN : 2506-6390

Traduction(s) :

"Le miroir aux alouettes" (Jan Kadar et Elmar Klos) : une leçon sur l'opportunisme provincial - URL :

https://journals.openedition.org/temoigner/7704 [fr]

Éditeur :

Éditions du Centre d'études et de documentation Mémoire d'Auschwitz, Éditions Kimé

Édition imprimée

Date de publication : 1 octobre 2018

Pagination : 14-18

ISBN : 978-2-930953-076

ISSN : 2031-4183

Référence électronique

Brecht Capiau, "The Shop on The High Street" (Jan Kadar \& Elmar Klos) : Een les in provinciaal opportunisme», Témoigner. Entre histoire et mémoire [Online], 127 | 2018, Online op 10 février 2022, geraadpleegd op 14 février 2022. URL: http://journals.openedition.org/temoigner/7699 ; DOI: https:// doi.org/10.4000/temoigner.7699 


\section{THE SHOP ON THE HIGH STREET}

(JAN KADAR \& ELMAR KLOS)

EEN LES IN PROVINCIAAL OPPORTUNISME

FILM 2018 is een zwart jaar voor de Poolse democratie en geschiedschrijving. In februari stemde de senaat een wetsvoorstel dat het mogelijk maakt om burgers die stellen dat het land medeschuldig is aan de Holocaust drie jaar in de gevangenis te stoppen. De ruk naar rechts in het Polen van president Andrzej Duda baart het Westen al langer zorgen, maar dit voorstel werd met opperste verbijstering ontvangen in politieke kringen. Polen heeft altijd al een ambique relatie gehad met de Tweede Wereldoorlog. Enerzijds is er de woede en de verbittering omwille van het feit dat Auschwitz, het bekendste concentratieen uitroeiingscentrum, zich op Pools grondgebied bevindt. Anderzijds kwamen de eerste rapporten over het bestaan van dit soort oorden van het Poolse verzet. Het aanvaarden en kunnen plaatsen van deze ambiguïteit helpt echter in de heling van dit internationale trauma. Een van de eerste films die het nationale verleden recht in de ogen keek en zelfs zorgde voor een verhoogde interesse in Holocaustfilms was de Tsjechoslowaakse prent The Shop on the High Street uit 1965 van Jan Kadar en Elmar Klos.

A FARAWAY COUNTRY

OF WHICH WE KNOW LITTLE'

O

alle nuances van de film te kunnen egrijpen en de complete afwezigheid, op een nobele uitzondering na, van nazi's en wastika's in een Holocaustfilm te duiden, is het noodzakelijk dat we een korte schets geven van de Tsjechoslovaakse geschiedenis van 1938 tot 1942 begint met het Verdrag van München op 30 september 1938. In dit verdran geven ber 1938. In dit verdrag geven de grote mogendheden, het Verenigd Koninkrijk, Frankrijk en Italiee, an nuitsin Tsjechoslowakije te annexeren Ze hopetenland in Tsjechoslowakije te annexeren. Ze hopen dat na de dit de latste Duitse anhechting zal zijn Bart 1938 dit verband is wellicht de foto warop de Bekend in mier Nevile Cham
Peace for our time belooft. Dat Tsjechoslowakije zelfs niet geraadpleegd wordt over deze aansluiting, is het minste van de premier zijn zorgen. Hij omschrijft het gebied immers als 'a faraway country of which we know little'.

In maart 1939 gaat Hitler nog een stap verder en oegt ook de rest van het land toe aan zijn Derde Rijk. Hierna beslist de Führer om Tsjechoslowakije op te denter kelijk. In we . mijn zijn nacht te verankene nakt Tiso gebruk van de Shop on The High Street Dene militie val speelt in The volks Thij met het volkspartij met het beruchte dubbele kruis als symbool verzorgt vanaf maart 1942 de Jodendeportatie in Slovakije. Als beloning verrijken de leden zich met onroerende goederen.
ANATOMIE VAN EEN PERSONAGE: ANTON 'TONO' BRTKO, DE 'PASSIEVE COLLABORATEUR'

Anton 'Tono' Brtko is het hoofdpersonage in de film. Tegelijk peet hij ook de symborische 'everyma,

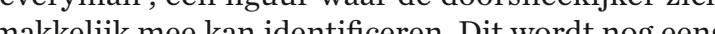
benadrubt door het feit dat we de naan van het dorp benadrij door het feit dat we de nave drie dingen in zijn leven: overeven, geen problents drie dingen in zijh leven. overleven, geen problemen

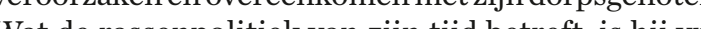
Wat de rassenpolitiek van zijn tijd betreft, is hij vij oppervlakkg. Tonowiler in bedekte ternen over pra war hij ceen invloed op heeft waar hijg geen invloed op heeft en waarhij zich ook niet Markus, de lokale Hirna Guard commandant, hem ark winkeltje de Arsche controleur te worden van het Rozali Lautmann Zijn vrouw Evelynabeshouwt Rozalia Lauthe sume als een geweldige opportuniteit on rijk te worden op . Hij vis bar

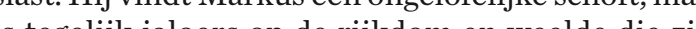
is tegelijk jaloers op de rijkdon en wijn coft heeft aangesloten bij de Hlinka Guard. Zijn beslissing om zich toch in te laten net de Jodenkwestie' is de eerste 'stepping stone' op hetpad naw zelfverloocheTwescinesinde

van de film tonen aan dat de Slovakse tinneman eigenlijk niet weet waa ij een Hitlerinitatieopvoor Man hus. Dit is een belangrijk gever zilo zulle re sociale regets aan zijh laars lapt. Je zou knn che welksoot mentingich eigenlikinl sène slant de tinn e doen. Boven. Kro dente de val Brtko heet. Krtko betekent 'mol' in het Slovaaks en onderstreeptnogmaals dat deman volledigblind is voor absurpijl lat hij zich gewillig betalen do de Joodse vuurpijl laat hij zich gewillig betalen door de Joodse keltjeinshan hor Hlinka Guard als met de Joden zonorter zowet met

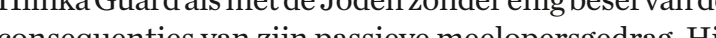
cordt
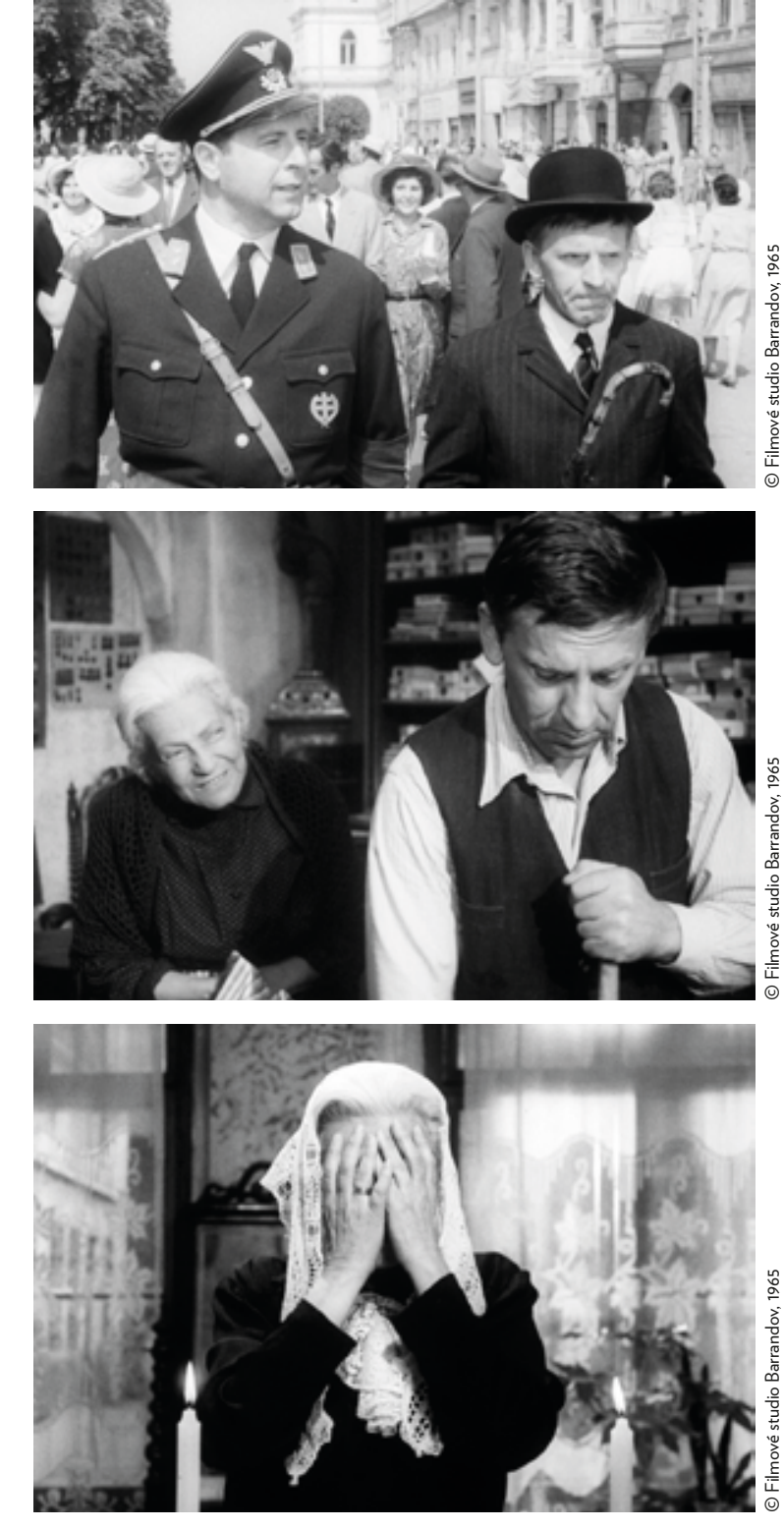

eroep op hem doen, waardoor er langzaam maar zeker en gewetenserosie ontstaat.

Een ander aspect van de rolprent die filncitic hebben angestipt is de religieuzecon het persong Jezus, denin een vijandige omgeving Ookhij wordtbespoten 
• op een bepaald moment krijgt hij zelfs het verwijt 'een martelaar' te zijn. De verwijzing naar de Jezusfiguur is echter dubbelzinnig. Regisseurs Jan Kadar en Elmar Klos corrumperen dit beeld en keren het binnenstebuiten. Zo is er een shot waarin Tono zijn voeten wast. Het wassen van zijn voeten in onschuld is echter, net als het wassen van de handen van Pontius Pilatus kort voor het uitleveren van Jezus aan zijn vijanden, niet meer dan een schaamlapje dat moet verbergen dat hij alleen verantwoordelijk is voor zijn desastreuze beslissingen. Het personage van Anton Brtko kunnen we dus eerder in verband brengen met de onwillige 'beul' Pontius Pilatus dan met zijn slachtoffer Jezus Christus. Als Brtko bovendien al een geloof aanhangt, dan kunnen we dit het best omschrijven als bijgeloof. Een mooie illustratie daarvan is het hoefijzer dat hij in het begin van de film over zijn schouder werpt als geluksbrenger.

Anton 'Tono' Brtko is niet door en door slecht. Hij verschuilt zich achter een muur van passieve fatsoenlijkheid, waardoor hij oogluikend dingen laat gebeuren die moreel niet te verantwoorden zijn. Dit is wellicht de hoofdreden waarom de film tot op vandaag een gevoelige snaar raakt. De quote van Edmund Burke dat de enige noodzakelijke vereiste om het kwaad te laten overwinnen goede mensen zijn die niets doen, is meer dan ooit van toepassing op onze Slovaakse timmerman.

\section{THE SHOP ON THE HIGH STREET: WEGBEREIDER VAN DE HOLOCAUSTFILM}

Het buitengewone succes van The Shop on The High Street betekende de doorbraak van de Tsjechoslowaakse film in de internationale cinema. Toch is de film ook een buitenbeentje in de filmstroming die later bekend zou staan als 'The Czechoslovakian New Wave', omdat regisseurs Jan Kadar en Elmar Klos geen deel uitmaken van de jonge garde die afstudeerde aan de Praagse filmschool in het begin van de jaren zestig. Beiden konden al een pak ervaring voorleggen met films als Kidnapped (1952) en The Accused (1964). Het kritische en commerciële succes van de film in de Verenigde Staten in 1966 en de daaropvolgende Oscar voor beste buitenlandse film verankerden de status van de film als moderne klassieker. De latere Oscarnominaties voor A Blonde In Love van Milos Forman en Closely Watched Trains van Jiri Menzel bevestigden dat de Tsjechoslowaakse film geen eendagsvlieg was.

Het succes van The Shop on The High Street had echter ook een donker randje. Na de Sovjetinvasie

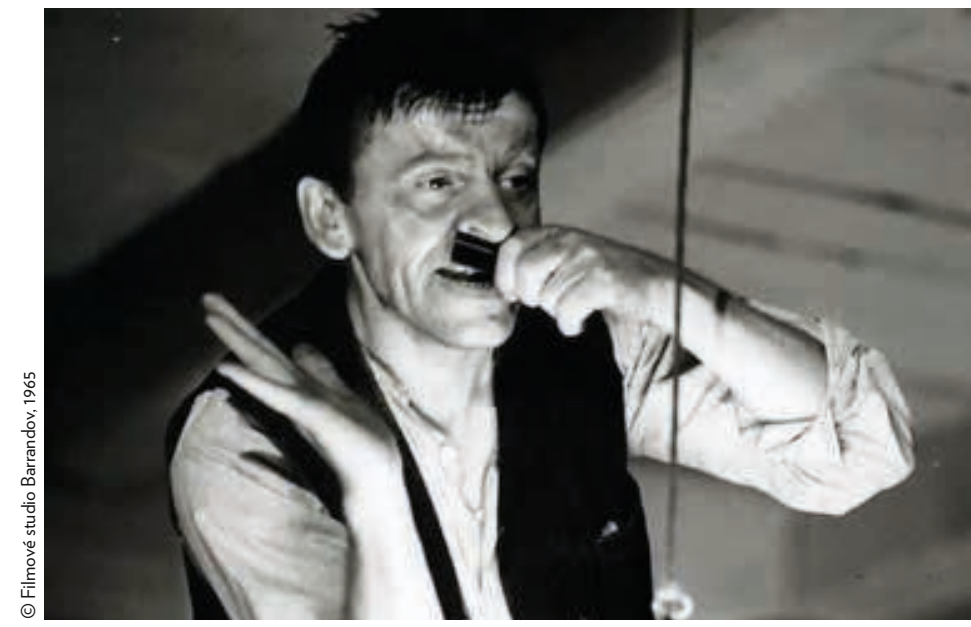

van 1968 in Tsjechoslowakije werd de film uit roulatie gehaald. In september 1969 emigreerde Jan Kadar, de onderdrukking beu, naar de Verenigde Staten, waar hij vooral carrière maakte met televisiefilms. Elmar Klos bleef in zijn geboorteland, maar kreeg af te rekenen met ontslag en tegenwerking. Geen van beiden zouden ooit nog het succes van The Shop on The High Street kunnen evenaren.

De film droeg in belangrijke mate bij tot een hernieuwde interesse in het maken van films met de Holocaust als onderwerp. Waar de rolprent vaak om wordt geprezen, is het vermijden van de sentimentele valkuil van het verzet van de 'eenzame held' waar veel latere films zoals Schindler's List wel intrappen. Het is juist de stilzwijgende toestemming van vele honderdduizenden mensen overal ter wereld, die de Holocaust mogelijk heeft gemaakt. The Shop on The High Street verbeeldt dat inzicht op een sobere en effectieve wijze, amper twintig jaar na het einde van de Tweede Wereldoorlog. Het drama behoort daarom tot het selecte kransje van films binnen de Holocaustcinema dat de tragedie terugbrengt tot haar kleinmenselijke proporties.

Brecht Capiau 